Received Date : 15-Apr-2016

Revised Date : 23-Jun-2016

Accepted Date : 06-Sep-2016

Article type : Original

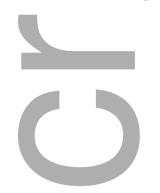

\title{
Nutritional Status and Weakness Following Pediatric Hematopoietic Cell Transplantation
}

Sandra Bouma MS, RDN, CSP ${ }^{1}$, Mark Peterson PhD MS ${ }^{2}$, Erin Gatza $\mathrm{PhD}^{1}$, Sung Won Choi MD MS ${ }^{1}$

1. Department of Pediatrics, Blood and Marrow Transplantation Program, University of Michigan, Ann Arbor, MI USA

2. Department of Physical Medicine and Rehabilitation, University of Michigan, Ann Arbor, MI USA

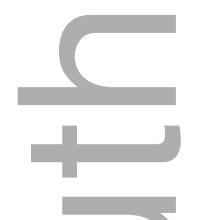

Running Title: Nutrition and Weakness after Pediatric HCT

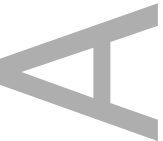

Abstract: $199 \quad$ Text: $3130 \quad$ Tables: 2

This is the author manuscript accepted for publication and has undergone full peer review but has not been through the copyediting, typesetting, pagination and proofreading process, which may lead to differences between this version and the Version of Record. Please cite this article as doi: $10.1111 /$ petr. 12821

This article is protected by copyright. All rights reserved 


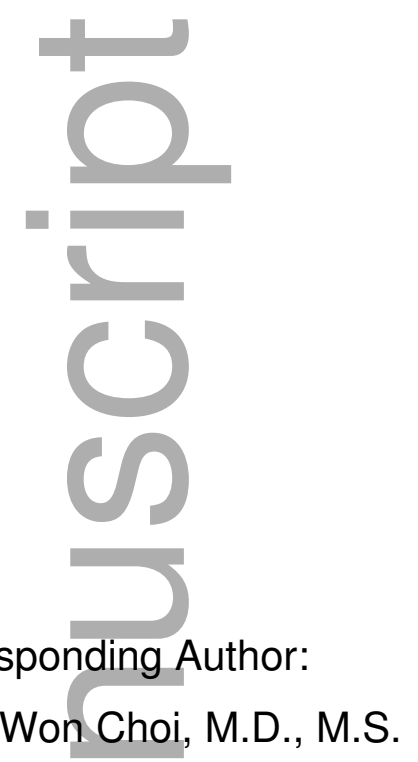

Corresponding Author:

Sung Won Choi, M.D., M.S.

Department of Pediatrics and Communicable Diseases

Blood and Marrow Transplantation Program

1500 E. Medical Center Dr.

D4118 Medical Professional Building, SPC 5718

Ann Arbor, MI 48109-5718

Phone: 734-615-5707 Fax: 734-615-0464

Email: sungchoi@med.umich.edu

Nutritional Status and Weakness Following Pediatric Hematopoietic Cell

Transplantation

Bouma S., Peterson M., Gatza E., Choi S.W.

Pediatric Transplantation

\section{ABSTRACT}


Survivorship after pediatric hematopoietic cell transplant (HCT) has increased over the past decade. Focus on long-term care and well-being remains critical due to risk of poor dietary habits and exaggerated sedentary behavior, which can lead to muscle weakness, increased risk for obesity and cardio-metabolic disorders. Nutrition and physical activity are key factors in survivorship; however, data are limited. Comprehensive nutritional assessments, including nutrition focused physical exam, grip strength and food/activity surveys, were completed in 36 pediatric HCT survivors (ages 2-25 years). Patients were divided into: under-nutrition, normal-nutrition and overnutrition categories. Fifty percent of participants were classified as normal-nutrition, 22\% under-nutrition, and $28 \%$ over-nutrition. Few patients met the U.S. Dietary Guidelines recommended intake for vegetables, fiber, saturated fat and SoFAS. Patients in the under-nutrition group demonstrated significantly lower grip strength than those in the normal- and over-nutrition groups. When grip strength was normalized to body mass, patients in the over-nutrition group had the highest prevalence of weakness. Using NHANES reference data, maximum grip strength and normalized grip strength cut-offs were identified that could significantly distinguish the nutrition groups. Comprehensive nutritional assessments and grip strength measurements are feasible, non-invasive, easy to perform and inform both under-and over-nutrition in pediatric HCT survivors.

Keywords: Hematopoietic Stem Cell Transplantation, Pediatrics, Child Malnutrition, Nutrition Assessment

\section{INTRODUCTION}

Children who receive hematopoietic cell transplants (HCT) are at high nutritional risk due to comorbidities and complications that are likely to develop before, during, and after transplant.(1,2) Energy imbalances from poor dietary habits and exaggerated sedentary behavior can result in substantial losses of lean body mass, muscle weakness, and functional impairments, placing survivors at risk for malnutrition, obesity and cardio-metabolic disorders.(3-6) While mounting evidence suggests that body habitus, nutritional status, dietary intake and physical activity throughout the HCT process are key factors in survivorship, there is a paucity of data in pediatric HCT patients. 
Body mass index (BMI) is the conventional method for determining body habitus, medication dosing, and nutritional status in HCT patients. Obesity, on the basis of BMI at the time of transplant, was associated with higher non-relapse mortality among pediatric and adult allogeneic HCT patients at our institution. Of the 101 pediatric patients included in the study, 32\% were determined to be overweight or obese based on their $\mathrm{BML}\left(>85^{\text {th }}\right.$ percentile).(7) Although $\mathrm{BMI}$ is a valid metric for stratifying the general population into different risk categories, it does not discriminate adipose tissue and muscle, nor does it allow identification of non-obese individuals with excess body fat. $(8,9)$ These shortcomings may be especially relevant among pediatric patients after $\mathrm{HCT}$, as shorter stature and stunting are documented latent outcomes. $(4,6)$

Alternative anthropometric and body composition measures, along with nutrition focused physical exam (i.e. assessment of fat and muscle wasting) and simple functional assessments, can more accurately determine nutritional status (under-, normal- and over-nutrition) and muscle weakness in children.(10-16) Grip strength is a functional assessment with excellent criterion validity and intra- and inter-rater reliability (17-21), and is correlated with nutritional status in adults.(22-25) In children and adolescents, grip strength is feasible to measure (26-30), and is highly correlated with total muscle strength (31). Normalized grip strength (grip strength/body mass) helps to identify weakness in overweight and obese adolescents and has been associated with cardiometabolic disorders.(15) New guidelines for diagnosing adult malnutrition (undernutrition) include both grip strength measurement and nutrition focused physical exam.(32) The pediatric malnutrition indicators do not yet include grip strength or nutrition focused physical exam, partly due to a lack of pediatric reference data at the time of development.(10, 14) However, reference charts for grip strength and normalized grip strength using National Health and Nutrition Examination Survey (NHANES) data from 2011-2012 (ages 6 - 80 years, by gender) recently became available (33), allowing standardized measure of grip strength in pediatric patients.

To date, using these alternative measures as part of a comprehensive nutritional assessment has not been reported in children undergoing HCT. Thus, we aimed to test 
the feasibility of incorporating nutrition focused physical exam and measures of grip strength and normalized grip strength as part of a comprehensive nutritional assessment in pediatric HCT patients.

\section{METHODS}

An exploratory, quality improvement investigation was conducted in survivors of pediatric hematopoietic cell transplant (ages 2-25 years). Patients were eligible to participate if they came to at least one regularly scheduled visit at a single universityaffiliated outpatient clinic during a study period of 30 consecutive clinic days. Participants provided written consent/assent for this feasibility study that was approved by our institutional review board in compliance with institutional regulations for the protection of human research participants. Comprehensive nutrition assessments were performed by a single registered dietitian with expertise in diagnosing adult and pediatric malnutrition, who also received advanced training on performing nutrition focused physical exam and measuring grip strength.(34) Nutrition assessment included: collecting anthropometric data (height, weight, mid upper arm circumference), obtaining medical and nutritional history, performing a nutrition focused physical exam, measuring grip strength, and having participants fill out an online food frequency questionnaire (BLOCK by NutritionQuest).(35) If participants were too young (typically $<10$ years old), caregivers filled out the BLOCK surveys on their behalf. Using BMI, nutrition focused physical exam and age-appropriate adult or pediatric characteristics of under-nutrition, patients were divided into three nutritional status categories: under-nutrition, normalnutrition and over-nutrition.(36) Medical and nutrition history was obtained through the medical chart and by interview with the participant and their family, if present at the appointment. A head-to-toe nutrition focused physical exam was performed by the registered dietitian who was trained using previously described techniques.(12, 37, 38) Nutrition focused physical exam was performed prior to measuring grip strength so as to minimize examination bias. 
Grip strength was measured using a calibrated JaymarPlus digitial hand dynamometer (Patterson Medical, Warrenville, IL), according to the American Society of Hand therapists measurement protocol, which has high intra-test and inter-test reliability.(17) Participants were encouraged to squeeze harder until the number on the digital read-out stopped rising.(39) The average of the three measurements $(\mathrm{kg})$ for each hand was compared to the reference data provided with the dynamometer. $(40,41)$ The highest measurement from either hand was used to determine the age and gender specific percentile for maximum grip strength and normalized grip strength (maximum grip strength/body mass) from the Peterson NHANES charts as per the NHANES protocol.(33) If a child was between an age or percentile category, the closest age or percentile category was selected. If the age or grip strength value was exactly midway between an age or percentile category, the lower category was selected. Because age and gender are the largest determinants of muscle strength, $(23,25)$ age and gender specific percentiles were calculated from NHANES reference data to allow comparisons across age groups. Cut offs of $<25^{\text {th }}$ percentile and $<10^{\text {th }}$ percentile were used to assess significant differences between the nutritional status groups. The conventional method of determining under-nutrition by using a cut off of more than 2 SD below the mean for age and gender per dynamometer manufacturer reference data were also recorded.(42)

Participants or their parents filled out online, validated food and activity screeners (BLOCK by NutritionQuest) (43)(44) using a laptop computer before the end of their clinic visit. Children, ages 2-17, used the BLOCK-Kids food and activity screener which is designed to assess usual dietary intake over the past 7 days. Young adults (18-25 years of age) used the BLOCK- Alive! food and physical activity screener which is designed to assess usual dietary intake over the past 3 months. The screeners assessed intake of fruit and fruit juices, vegetables, potatoes, whole grains, meat/poultry/fish, dairy, legumes, saturated fat, added sugars, glycemic load and glycemic index. The screeners also estimate daily calories (kcals), protein and sugary beverage (both $\mathrm{kcal}$ and frequency) intake based on patient-reported intake. The physical activity portion of the BLOCK-Kids screener queries frequency and duration of 
activities and the amount of screen time (television, video games, computer) per day, over the past week. The adult screener includes the frequency and duration of jobrelated, daily life and leisure activities during the past 3 months. The participants were provided with a summary print out of the online screener results. Participant data were downloaded from the password protected NutritionQuest research portal for analysis.

Under-nutrition for young adult participants (18-25 years of age) was determined using the American Society of Parenteral and Enteral Nutrition (A.S.P.E.N.)/Academy of Nutrition and Dietetics (Academy) workgroup's adult characteristics of malnutrition, as previously described (32). Participants who were 2-17 years old were assessed for under-nutrition using MTool ${ }^{\mathrm{TM}}$, the University of Michigan Health System's pediatric malnutrition diagnostic tool.(11) MTool ${ }^{\mathrm{TM}}$ is based on the evidence informed, consensus derived definition of pediatric malnutrition endorsed by A.S.P.E.N., the Academy and the American Academy of Pediatrics.(14) MToolTM assesses z-scores for BMI/weightfor-length ratio, weight, height and mid upper-arm circumference, weight loss, growth velocity, dietary intake and illness-related metabolic stress. The indicators used with MTool ${ }^{\mathrm{TM}}$ are closely aligned with the indicators of pediatric malnutrition published in a consensus statement of the A.S.P.E.N./Academy pediatric malnutrition workgroup (10), but $\mathrm{MToo}^{\mathrm{TM}}$ additionally includes nutrition focused physical exam, and markers for diagnosing overweight and obesity associated with stunting. (11) Over-nutrition was defined in young adults (18-25 years) as BMI $\geq 25 \mathrm{~kg} / \mathrm{m}^{2}$ and in children (2-17 years) as a $z$ score $\geq 1$ along with evidence of subcutaneous body fat on physical exam.(45) All statistical analyses were conducted using SAS 9.3 (SAS Institute, Cary, NC). Differences across nutritional status categories were tested using two samples t-tests and chi-squared tests for continuous and categorical variables, respectively. A $p$ value $<0.05$ was considered statistically significant.

\section{RESULTS}

Thirty-eight patients were approached to participate in the comprehensive nutrition assessments and all agreed to participate. Two could not complete the assessment 
and one patient could not complete the food survey due to time constraints (i.e. having to get to another medical appointment). In total, 36 patients were included in our study. Patient and transplant characteristics are reported in Table 1. Twenty-four (66.7\%) participants were male, 12 (33.3\%) were female. Participants had a median age of 16 years with a median time since transplant of 636 days. Seventy-five percent $(n=27)$ of participants were white and non-Hispanic. The majority of patients received an HLAmatched HCT from a related $(n=10)$ or unrelated $(n=20)$ donor after full intensity conditioning ( $n=22)$. Sixty-one percent of participants received a HCT as treatment for a malignant diagnosis; 39\% $(n=14)$ had a diagnosis that was non-malignant. Seventeen participants (47.2\%) had a history of acute graft-versus-host disease (GVHD), 21 had a history of chronic GVHD, and 9 (25\%) never had GVHD. Twenty participants (55.6\%) had active GVHD, requiring therapy with corticosteroids, at the time of this study. No statistically significant differences in age, race, malignant or non-malignant diagnosis, HCT donor or conditioning, or GVHD were detected between male and female participants $(p>0.05)$.

The weight status, nutritional status and dietary intake for study participants are summarized in Table 1. Only 2 male participants were underweight. Fifty-six percent of the group were normal weight $(n=20)$; however, more female than male participants were normal weight $(83.3 \%$ vs $41.7 \% ; p<0.05)$. Conversely, more male than female participants were overweight or obese $(50.0 \%$ vs $16.7 \%$; $p<0.05)$. Correspondingly, significantly more male than female participants were categorized as over-nutrition $(37.5 \%$ vs $8.3 \% ; p<0.05)$. No significant differences between male and female participants were observed in the normal nutrition and under-nutrition categories. In all, $50 \%$ of participants were categorized as normal nutrition, $28 \%$ as over-nutrition, and $22 \%$ as under-nutrition.

Overall, dietary intake was below the 2015 U.S. Dietary Guideline's recommended amounts. Only one quarter of participants met the 2015 U.S. Dietary Guidelines recommended intake for fruit $(n=9 ; 25.7 \%)$. An even smaller percentage of participants met the recommended intake for vegetables (11.4\%), fiber $(2.9 \%)$, saturated fat $(8.6 \%)$ 
and solid fat and added sugars (8.6\%). However, female participants were more likely than male to meet the recommended intake for fruit ( $45.5 \%$ vs $16.7 \%)$, vegetables $(36.4 \%$ vs $0.0 \%)$ and saturated fat intake $(27.3 \%$ vs $0.0 \%)$. Less than half of the crosssectional cohort ate as well as $50 \%$ of those in the U.S. population of the same age and gender as reported in the National Health And Nutrition Survey of $2007-2011$. (46)

Participants' grip strength differed significantly by nutrition status (Table 2). Grip strength among individuals in the under-nutrition group was significantly lower than the other two groups, with $75 \%$ of the under-nutrition group having a grip strength $<25^{\text {th }}$ percentile for age/gender compared to a U.S. reference population.(33) Using recently published NHANES reference data, a maximum grip strength cut-off of less than the $10^{\text {th }}$ percentile for age/gender significantly distinguished the under-nutrition group from

the normal and over-nutrition groups $(62.5 \%$ vs $26.7 \%$ and $25.0 \%$, respectively; $p<$ 0.05). This difference was also significant using the conventional cut-off point of $>2$ standard deviations (SD) below the mean of age- and gender-matched dynamometer reference data.

When grip strength was normalized to body mass (maximum grip strength/body mass; NGS), patients in both the under-nutrition and over-nutrition groups demonstrated weakness compared to patients in the normal nutrition group $(p<0.05)$. A normalized grip strength cut-off of less than the $25^{\text {th }}$ percentile for age/gender significantly differentiated the over-nutrition group from normal nutrition group $(62.5 \%$ vs $13.3 \%, p<$ 0.05).

Finally, participants in the normal-nutrition group spent more time engaged in physical activity, while those in the under-nutrition group spent significantly more hours of the day viewing a screen.

\section{DISCUSSION}

Health maintenance behaviors, such as eating a nutrient dense diet and participating in physical activity, have not traditionally been emphasized during pediatric HCT. In this study, HCT survivors consumed a diet that was well below recommended intakes and 
were at risk for significant muscle weakness. Less than $12 \%$ of our patients met the 2015 U.S. Dietary Guidelines for key dietary components. Males and females had significant differences in intake for a few key nutrients; however, there were no statistically significant differences in dietary intake across nutritional status (data not shown). To discern these differences, a larger, sufficiently powered study using the BLOCK screeners or perhaps using the "gold standard" dietary intake method, i.e. a 3-5 day 24 hour recall would be required (e.g. Automated Self-Administered 24 hour recall; ASA24-2016, National Cancer Institute).

The nutrition focused physical exam, which includes a hands-on assessment of muscle and fat wasting, can be used to detect muscle tone and presence of body fat. Using nutrition focused physical exam criteria, three patients that had been categorized as "overweight", by BMI or BMI z-score, were re-categorized into the normal-nutrition group due to having a lean, muscular build on physical exam, plus reporting regular participation in resistance training and physical activity. Of interest, another patient in the normal-nutrition group, who was regaining weight after experiencing under-nutrition, demonstrated continued mild-to-moderate muscle wasting, but also had early signs of fat accumulation. This patient also had low handgrip strength measurements, leading us to suspect normal weight obesity.

Measuring grip strength with a hand dynamometer is well received by individuals and takes less than 5 minutes to perform. $(16,23)$ Grip strength has excellent criterion validity and intra- and inter-rater reliability. $(17,18,20,21)$ This cross-sectional study showed that grip strength correlated with under-nutrition, consistent with reports in the adult literature.(22-25) Because grip strength can vary by age and gender, reference tables that use percentiles are helpful in the clinical setting. Using a maximum grip strength cut-off of $<10^{\text {th }}$ percentile for age and gender may help detect patients who are under-nourished. Even though a maximum strength cut off of $<10^{\text {th }}$ percentile and the conventional method (average grip strength $>$ 2SD below the mean reference data provided with the dynamometer) were both statistically significant, percentiles may detect subtler changes in grip strength. Moreover, the NHANES data draws from a 
larger, more contemporary data set (7,119 individuals, 2011-2012).(33) The reference data provided with the JaymarPlus digital dynamometer was from a smaller, older sample $(1,109$ individuals, mid-1980's).(40,41) In our study, the only patient in the under-nutrition group who did not demonstrate weakness $\left(<10^{\text {th }}\right.$ percentile for grip strength) had a grip strength in the $75^{\text {th }}$ percentile and a NGS in the $90^{\text {th }}$ percentile, leading us to suspect that perhaps he was not as malnourished as the pediatric malnutrition indicators suggested. A future study using a larger sample size could test if a maximum grip strength of less than the $10^{\text {th }}$ percentile for age/gender may be an indicator of pediatric under-nutrition.

To our knowledge, this is the first study to compare normalized grip strength with nutritional status. We found that normalized grip strength distinguished between the normal and over-nutrition group, suggesting that normalized grip strength may be useful in determining weakness in overweight and obese pediatric HCT patients. Normalized grip strength has been shown to help detect patients who are at risk of cardio-metabolic diseases.(15) In our study, a normalized grip strength cut-off of $25^{\text {th }}$ percentile for age and gender differentiated the over-nutrition group from the normal-nutrition group.

Validated Food Frequency Questionnaires, such as Block by NutritionQuest, take little time to administer and were well-received by our patients. Caregivers stated they appreciated having individualized nutrition education based on the results of the Food Frequency Questionnaires. While Food Frequency Questionnaires are not designed to compute exact calorie and protein information, they can be useful for determining dietary quality and to elucidate changes in an individual's dietary intake.

This study, although limited by the descriptive, cross-sectional design, showed the feasibility of using handgrip dynamometry, nutrition focused physical exam, and online food and activity surveys as part of a comprehensive nutritional assessment. Future research is needed to determine which indicators are most correlated with nutritional status and weakness, and the temporal sequence of these changes throughout the HCT process. To that end, our institution is conducting a longitudinal study looking at $\underline{\text { Clinical }}$ Outcomes, Nutrition, Exxercise and Psychosocial factors in pediatric hematopoietic cell 
Transplant (CONSEPT Study, registered at ClinicalTrials.gov, NCT02734797). A larger sample size could potentially validate which grip strength and normalized grip strength cut-off values are best at detecting malnutrition and cardio-metabolic risk in pediatric HCT patients. These data can be useful in designing individualized, targeted interventions to help prevent muscle loss and fat accumulation. Clinical trials are needed to determine if health-enhancing behaviors can prevent malnutrition and weakness, and improve clinical outcomes during survivorship.

\section{AUTHORSHIP}

S. Bouma enrolled participants onto the study, performed all clinical assessments (including nutrition focused physical exam, grip strength), administered food and activity online surveys, and managed participant data. M. Peterson performed all statistical analyses. All authors (S. Bouma, M.D. Peterson, E. Gatza and S.W. Choi) contributed to research study design, the analysis and interpretation of data, and to drafting, critical review, revising and approval of the submitted version of the manuscript. This study was supported by a grant from the Hyundai Hope On Wheels (S.W. Choi).

\section{CONFLICT OF INTEREST}

None of the authors have any conflicts of interest.

\section{REFERENCES}

1. Bollard C, Krance R, Heslop h. Hematopoietic stem cell transplantation in pediatric oncology. Principles and practice of pediatric oncology 5th ed Philadelphia: Lippincott Williams \& Wilkins 2006: 476-500.

2. SMITH FO, REAMAN GH, RACADIO JM. Hematopoietic Cell Transplantation in Children with Cancer: Springer, 2014.

3. White M, Murphy A, hallahan A, Ware R, Fraser C, Davies P. Survival in overweight and underweight children undergoing hematopoietic stem cell transplantation. European journal of clinical nutrition 2012: 66: 1120-1123. 
4. Mostoufi-MoAb S, Ginsberg JP, Bunin N, et al. Body composition abnormalities in long-term survivors of pediatric hematopoietic stem cell transplantation. The Journal of pediatrics 2012: 160: 122128.

5. Sharma TS, Bechard LJ, Feldman HA, et al. Effect of titrated parenteral nutrition on body composition after allogeneic hematopoietic stem cell transplantation in children: a double-blind, randomized, multicenter trial. The American journal of clinical nutrition 2012: 95: 342-351.

6. WiLHELMSSON M, VATANEN A, BORGSTRÖM B, et al. Adverse health events and late mortality after pediatric allogeneic hematopoietic SCT-two decades of longitudinal follow-up. Bone marrow transplantation 2015: 50: 850-857.

7. GLeIMER M, LI Y, CHANG L, et al. Baseline body mass index among children and adults undergoing allogeneic hematopoietic cell transplantation: clinical characteristics and outcomes. Bone marrow transplantation 2015: 50: 402-410.

8. JAVED A, JUMEAN M, MuRAD M, et al. Diagnostic performance of body mass index to identify obesity as defined by body adiposity in children and adolescents: a systematic review and metaanalysis. Pediatric obesity 2015: 10: 234-244.

9. Yeoh AJ, Pedley A, Rosenquist KJ, hoffmann U, Fox CS. The Association Between Subcutaneous Fat Density and the Propensity to Store Fat Viscerally. The Journal of clinical endocrinology and metabolism 2015: 100: E1056-1064.

10. BeCKER PJ, CARney LN, Corkins MR, et al. Consensus statement of the Academy of Nutrition and Dietetics/American Society for Parenteral and Enteral Nutrition: indicators recommended for the identification and documentation of pediatric malnutrition (undernutrition). Journal of the Academy of Nutrition and Dietetics 2014: 114: 1988-2000.

11. BoumA S. M-Tool Michigan's Malnutrition Diagnostic Tool. ICAN: Infant, Child, \& Adolescent Nutrition 2014: 6: 60-61.

12. CORKINS KG. Nutrition-Focused Physical Examination in Pediatric Patients. Nutrition in Clinical Practice 2015: 30: 203-209.

13. Fields DA, Gunatilake R, Kalaitzoglou E. Air Displacement Plethysmography Cradle to Grave. Nutrition in Clinical Practice 2015: 30: 219-226.

14. MeHTA NM, CoRkINS MR, LymAn B, et al. Defining Pediatric Malnutrition A Paradigm Shift Toward Etiology-Related Definitions. Journal of Parenteral and Enteral Nutrition 2013: 37: 460-481.

15. Peterson MD, Saltarell WA, Visich PS, Gordon PM. Strength capacity and cardiometabolic risk clustering in adolescents. Pediatrics 2014: 133: e896-903.

This article is protected by copyright. All rights reserved 
16. RusSell MK. Functional Assessment of Nutrition Status. Nutrition in Clinical Practice 2015: 30: 211-218.

17. Mathiowetz V, Weber K, Volland G, Kashiman N. Reliability and validity of grip and pinch strength evaluations. The Journal of hand surgery 1984: 9: 222-226.

18. RUIZ JR, CASTRO-PIÑERO J, ESPAÑA-ROMERO V, et al. Field-based fitness assessment in young people: the ALPHA health-related fitness test battery for children and adolescents. British journal of sports medicine 2010: bjsports75341.

19. Bellace JV, Healy D, Besser MP, Byron T, hohman L. Validity of the Dexter Evaluation System's Jamar dynamometer attachment for assessment of hand grip strength in a normal population. Journal of Hand Therapy 2000: 13: 46-51.

20. PEOLSSON A, HEDLUND R, ÖBERG B. Intra-and inter-tester reliability and reference values for hand strength. Journal of Rehabilitation Medicine 2001: 33: 36-41.

21. MATHIOWETZ V. Comparison of Rolyan and Jamar dynamometers for measuring grip strength. Occupational therapy international 2002: 9: 201-209.

22. JAKOBSEN LH, RASK IK, KONDRUP J. Validation of handgrip strength and endurance as a measure of physical function and quality of life in healthy subjects and patients. Nutrition 2010: 26: 542-550.

23. Norman K, StobäUs N, Gonzalez MC, Schulzke J-D, Pirlich M. Hand grip strength: outcome predictor and marker of nutritional status. Clinical nutrition 2011: 30: 135-142.

24. Mendes J, Azevedo A, Amaral TF. Handgrip strength at admission and time to discharge in medical and surgical inpatients. Journal of Parenteral and Enteral Nutrition 2014: 38: 481-488.

25. Guerra RS, Fonseca I, Pichel F, Restivo Mt, Amaral TF. Handgrip strength and associated factors in hospitalized patients. Journal of Parenteral and Enteral Nutrition2015. p. 322-330

26. De Souza MA, Benedicto MMB, Pizzato TM, Mattiello-SverzUt AC. Normative data for hand grip strength in healthy children measured with a bulb dynamometer: a cross-sectional study. Physiotherapy 2014: 100: 313-318.

27. Selles RW, Zuidam JM, Willemsen SP, Stam HJ, Hovius SE. Growth diagrams for grip strength in children. Clinical Orthopaedics and Related Research ${ }^{\circledR}$ 2010: 468: 217-223.

28. Newman DG, Pearn J, Barnes A, Young C, Kehoe M, Newman J. Norms for hand grip strength. Archives of disease in childhood 1984: 59: 453-459.

This article is protected by copyright. All rights reserved 
29. Serrano MM, Collazos JR, Romero SM, et al. Dinamometría en niños y jóvenes de entre 6 y 18años: valores de referencia, asociación con tamaño y composición corporal. Anales de pediatría: Elsevier; 2009. p. 340-348.

30. Hébert LJ, Maltais dB, lepage C, Saulnier J, Crête M, Perron M. Isometric Muscle Strength in Youth Assessed by Hand-held Dynamometry: A Feasibility, Reliability, and Validity Study: A Feasibility, Reliability, and Validity Study. Pediatric Physical Therapy 2011: 23: 289-299.

31. WIND AE, TAKKEN T, HELDERS PJ, ENGELBERT RH. Is grip strength a predictor for total muscle strength in healthy children, adolescents, and young adults? European journal of pediatrics 2010: 169: 281-287.

32. White JV, GUenter P, Jensen G, et al. Consensus statement of the academy of nutrition and dietetics/american society for parenteral and enteral nutrition: characteristics recommended for the identification and documentation of adult malnutrition (undernutrition). Journal of the Academy of Nutrition and Dietetics 2012: 112: 730-738.

33. Peterson MD, KRISHNAN C. Growth Charts for Muscular Strength Capacity With Quantile Regression. American journal of preventive medicine 2015: 49: 935-938.

34. http://www.eatrightpro.org/resource/career/professional-development/face-to-facelearning/nfpe-workshop. Last accessed June 23, 2016.

35. http://www.nutritionquest.org/

36. PMNCH Knowledge Summary 18: Women's and Children's Health - Nutrition. 2012. Last Accessed April 16, 2016. http://www.who.int/pmnch/topics/part publications/KS18-high.pdf

37. Fischer M, JeVenn A, HiPSkIND P. Evaluation of muscle and fat loss as diagnostic criteria for malnutrition. Nutrition in Clinical Practice 2015: 30: 239-248.

38. SECKER DJ, JEEJEEBHOY KN. How to perform subjective global nutritional assessment in children. Journal of the Academy of Nutrition and Dietetics 2012: 112: 424-431. e426.

39. ROBERTS HC, DENISON HJ, MARTIN HJ, et al. A review of the measurement of grip strength in clinical and epidemiological studies: towards a standardised approach. Age and ageing 2011: afr051.

40. Mathiowetz V, Kashman N, Volland G, Weber K, Dowe M, Rogers S. Grip and pinch strength: normative data for adults. Arch Phys Med Rehabil 1985: 66: 69-74.

41. MATHIOWETZ V, WIEMER DM, FEDERMAN SM. Grip and pinch strength: norms for 6-to 19-year-olds. American Journal of Occupational Therapy 1986: 40: 705-711.

42. Bin CM, Flores C, Álvares-da-Silva MR, Francesconi CFM. Comparison between handgrip strength, subjective global assessment, anthropometry, and biochemical markers in assessing nutritional 
status of patients with Crohn's disease in clinical remission. Digestive diseases and sciences 2010: 55: 137-144.

43. Hunsberger M, O'MAlLey J, BLock T, NorRIS JC. Relative validation of Block Kids Food Screener for dietary assessment in children and adolescents. Maternal \& child nutrition 2015: 11: 260-270.

44. Block G, Hartman AM, Naughton D. A reduced dietary questionnaire: development and validation. Epidemiol 1990; 1:58-64.

45. OnIS MD, ONYANGo AW, Borghi E, SiYAm A, NiShida C, SiekMANn J. Development of a WHO growth reference for school-aged children and adolescents. Bulletin of the World Health Organization 2007: 85: 660-667.

46. http://epi.grants.cancer.gov/diet/usualintakes/pop/2007-10/index.html. Last accessed June 23. 2016.
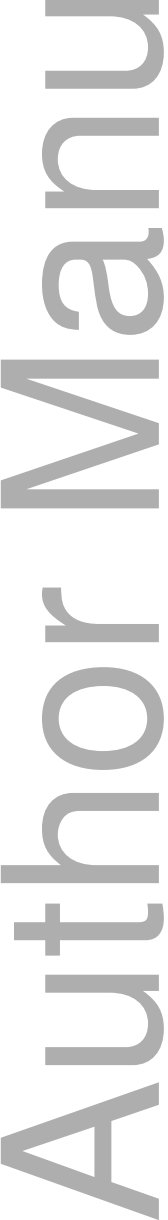

This article is protected by copyright. All rights reserved 
Table 1. Weight, nutritional and transplant characteristics of a cross-sectional sample of pediatric HCT survivors

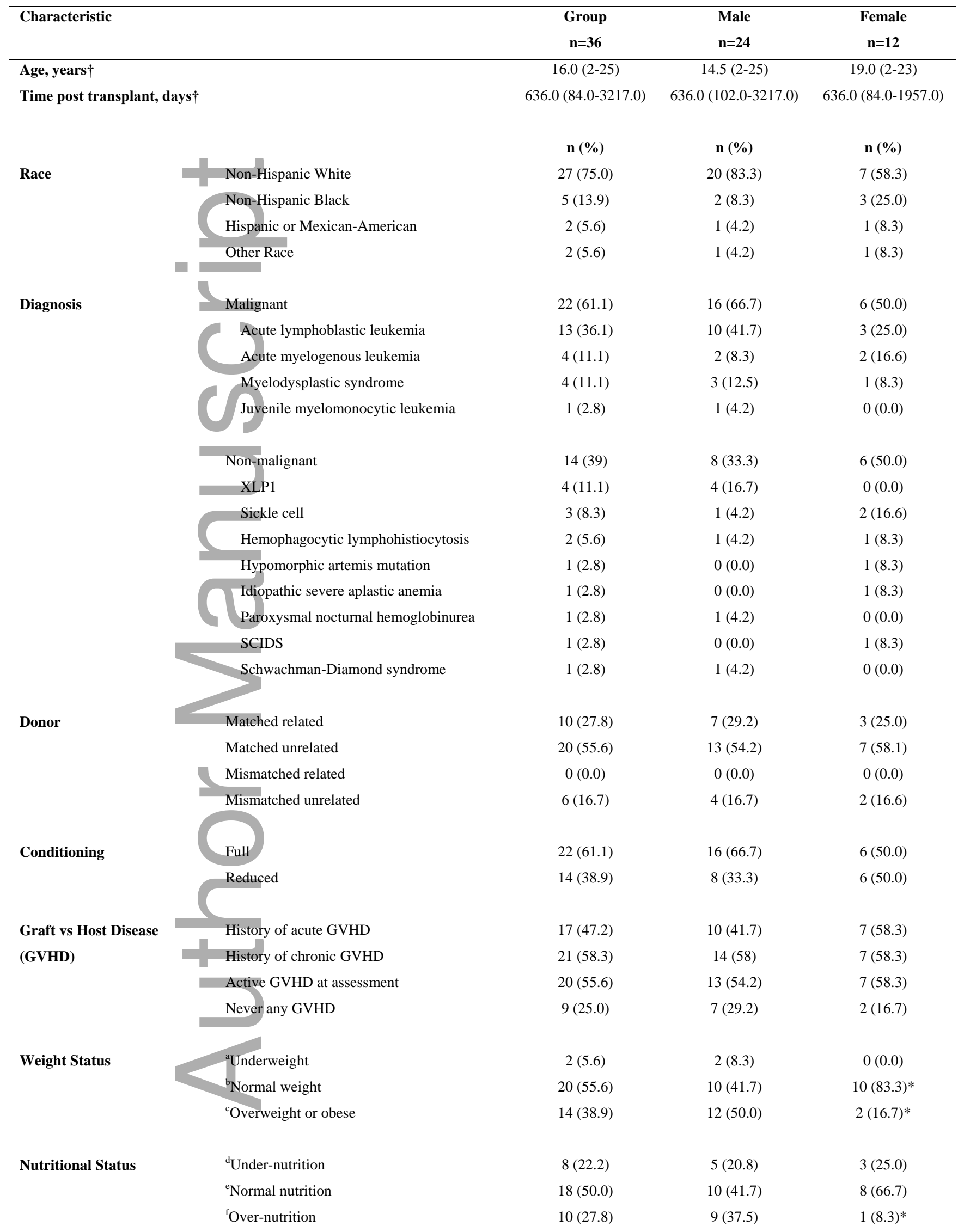

Dietary Intake ${ }^{\mathrm{g}}$

${ }^{\mathrm{h}}$ Met recommendations for: 


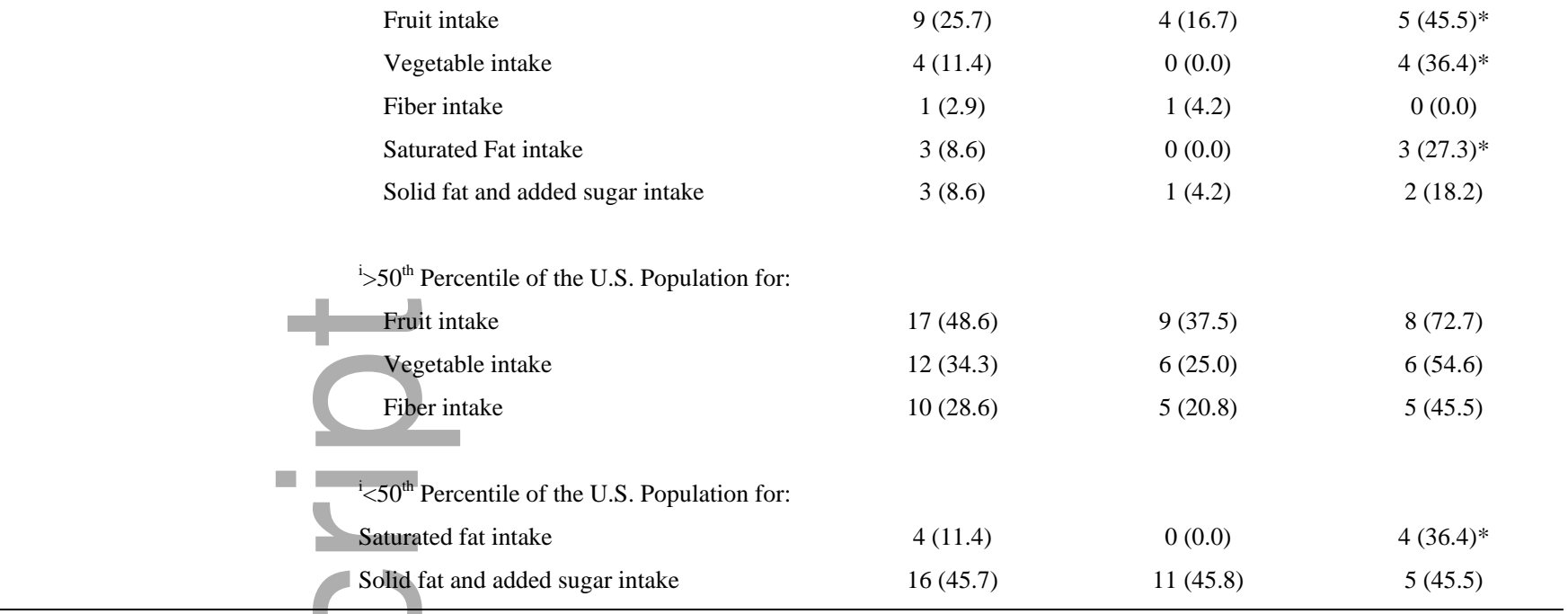

*Significant difference between males and females $(\mathrm{p}<0.05)$

$\dagger$ Median (range)

${ }^{\mathrm{a}} \mathrm{BMI}<18.5 \mathrm{~kg} / \mathrm{m}^{2}$ ( $\geq 18$ years old) or BMI $\mathrm{z}$-score $<-1$ ( $<18$ years old $)$

${ }^{\mathrm{b}}$ BMI $18.5-24.9 \mathrm{~kg} / \mathrm{m}^{2}$ ( $\geq 18$ years old) or BMI z-score -0.99 to +0.99 ( $<18$ years old $)$

${ }^{\mathrm{c}} \mathrm{BMI} \geq 25 \mathrm{~kg} / \mathrm{m}^{2}$ ( $\geq 18$ years old) or BMI $\mathrm{z}$-score $\geq 1$ ( $<18$ years old)

${ }^{\mathrm{d}}$ Per the previously described adult under-nutrition characteristics ${ }^{14}$ and pediatric under-nutrition indicators ${ }^{23,27}$

${ }^{\mathrm{e}}$ No under-nutrition or over-nutrition

${ }^{\mathrm{f}} \mathrm{BMI}=\mathrm{BMI} \geq 25 \mathrm{~kg} / \mathrm{m}^{2}$ ( $\geq 18$ years old) or BMI z-score $\geq 1$ ( $<18$ years old) PLUS no PCM, no evidence of strong, lean body habitus on physical exam and no report of engaging in intense physical activity training.

${ }^{\mathrm{g}} \mathrm{n}=35$

${ }^{\text {h}}$ U.S. Department of Health and Human Services and U.S. Department of Agriculture. 2015 - 2020 Dietary Guidelines for Americans. $8^{\text {th }}$ Edition. December 2015. Available at http://health.gov/dietaryguidelines/2015/guidelines/. Accessed June 23, 2016.

${ }^{i}$ Usual Dietary Intakes: Food Intakes, U.S. Population, 2007-10. Epidemiology Research Program Web site. National Cancer Institute. http://epi.grants.cancer.gov/diet/usualintakes/pop/2007-10/index.html Updated May 20, 2015. Accessed June 23, 2016.

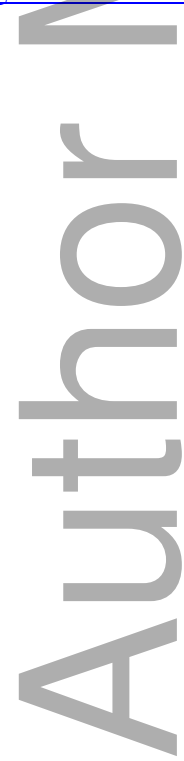


Table 2. Muscle strength \& physical activity stratified for nutritional status in patients $>6$ years old

\begin{tabular}{|c|c|c|c|}
\hline & $\begin{array}{l}\text { Under-Nutrition } \\
\qquad n=8\end{array}$ & $\begin{array}{l}\text { Normal-nutrition } \\
\qquad \mathbf{n}=15\end{array}$ & $\begin{array}{c}\text { Over- } \\
\text { Nutrition } \\
\text { n=8 }\end{array}$ \\
\hline Grip Strength, kg & $20.71 \pm 14.74$ & $33.08 \pm 14.74 *$ & $33.99 \pm 14.04^{\dagger}$ \\
\hline a Grip Strength<25th Percentile (for age \& sex), \% & 75.0 & 40.0 & 37.5 \\
\hline a Grip Strength<10th Percentile (for age \& sex), \% & 62.5 & $26.7 *$ & $25.0^{\dagger}$ \\
\hline Normalized Grip Strength (NGS) & $0.47 \pm 0.17$ & $0.56 \pm 0.16^{* \S}$ & $0.40 \pm 0.14$ \\
\hline${ }^{\text {a }}$ GGS $<25$ th Percentile (for & 37.5 & $13.3^{\S}$ & 62.5 \\
\hline${ }^{\text {a }}$ NGS $<10$ th Percentile (for age and sex), \% & 25 & $6.7^{\S}$ & 62.5 \\
\hline Grip Strength, Right hand, > 2 SD below the norm, \% & 87.5 & $6.7 *$ & $12.5^{\dagger}$ \\
\hline Grip Strength, Left hand, > 2SD below the norm, $\%$ & 50.0 & $13.3^{*}$ & $12.5^{\dagger}$ \\
\hline Moderate-to-Vigorous Physical Activity (MVPA), min & $8.62 \pm 9.20$ & $88.22 \pm 69.66^{* \S}$ & $39.10 \pm 30.82$ \\
\hline${ }^{\mathrm{b}}$ Television/Screen Viewing Time, hours & $5.67 \pm 0.58^{*}$ & $4.00 \pm 1.00$ & $4.40 \pm 1.52$ \\
\hline
\end{tabular}

Abbreviations: BMI, body mass index; GVHD, graft versus host disease; MVPA, moderate to vigorous physical activity;

NGS, normalized grip strength (i.e. grip strength/body mass)

${ }^{a}$ Percentiles from NHANES 2011-2012 population level reference data, as reported by Peterson and Krishnan, 2015

${ }^{\mathrm{b}}$ Among children/adolescents $<18$ years old $(\mathrm{n}=17)$

*Significant difference between under-nutrition and normal-nutrition groups $(\mathrm{p}<0.05)$

$\dagger$ Significant difference between under-nutrition and over-nutrition groups $(\mathrm{p}<0.05)$

$\S$ Significant differences between normal-nutrition and over-nutrition groups $(\mathrm{p}<0.05)$ 